\title{
The influence of hypoglycaemia on regional cerebral blood flow and cerebral volume in Type 1 (insulin-dependent) diabetes mellitus
}

\author{
G. Tallroth ${ }^{1}$, E. Ryding ${ }^{2}$, C-D. Agardh ${ }^{1}$ \\ ${ }^{1}$ Department of Internal Medicine, University Hospital, Lund, Sweden \\ ${ }^{2}$ Department of Clinical Neurophysiology, University Hospital, Lund, Sweden
}

\begin{abstract}
Summary. The effect of moderate hypoglycaemia (venous blood glucose $2.0 \pm 0.2 \mathrm{mmol} / 1$; mean $\pm \mathrm{SD}$ ) on regional cerebral blood flow and cerebral volume was studied in a group of ten right-handed patients with Type 1 (insulin-dependent) diabetes mellitus (age 26.0 \pm 2.4 years, duration $18.4 \pm$ 3.8 years) using an intravenous Xenon 133 single photon emission computed tomography technique. After $10 \mathrm{~min}$ of hypoglycaemia, global cerebral blood flow had increased to $55.8 \pm 4.5 \mathrm{ml} \cdot 100 \mathrm{~g}^{-1} \cdot \mathrm{min}^{-1}$ compared to the initial normoglycaemic flow of $49.5 \pm 3.7 \mathrm{ml} \cdot 100 \mathrm{~g}^{-1} \cdot \min ^{-1}(p<0.01)$. A further increase in global cerebral blood flow to $59.5 \pm 4.5 \mathrm{ml} \cdot 100 \mathrm{~g}^{-1} \cdot \mathrm{min}^{-1}(p<0.05)$ occurred $15 \mathrm{~min}$ after normalization of the blood glucose level. The global cerebral blood flow change from before hypoglycaemia to after re-
\end{abstract}

covery was inversely related to the initial glucose level. No change in the relative distribution of the regional cerebral blood flow was found between the measurements. The cerebral blood flow was significantly higher in the right hemisphere compared with the left hemisphere $(2.3,1.6$ and $2.2 \%$, respectively; $p<0.05$ ) in all measurements. Deeper hypoglycaemia was associated with a more pronounced decrease in brain volume, while the length of the restitution time after hypoglycaemia correlated with a volume increase. Due to influences with opposite effects there was no mean change in the brain volume.

Key words: Hypoglycaemia, cerebral blood flow, brain volume.
Hypoglycaemia is a common and potentially dangerous effect of treatment with insulin. Since the brain is critically dependent upon glucose for its oxidative metabolism severe hypoglycaemia ultimately leads to cerebral dysfunction and cell death. Moderate hypoglycaemia, i.e. blood glucose levels around $3.0 \mathrm{mmol} / \mathrm{l}$, leads to alterations in cognitive performance initially affecting attention and concentration [1,2]. Neurophysiological studies have shown slowing of electrocortical activity and changes in event-related potentials also during moderate hypoglycaemia [3-5]. Recovery from cerebral dysfunction seems to lag behind restitution of plasma glucose [5].

From animal studies, it is known that cerebral blood flow (CBF) can be increased markedly following acute severe hypoglycaemia and is followed by a delayed hypoperfusion [6,7]. Relatively little attention has been paid to changes in CBF in man during hypoglycaemia. Some of the information stems from studies of CBF in therapeutic insulin coma and in healthy control subjects, in which increments in flow have been observed [8-10]. A considerable proportion of insulin-treated diabetic patients frequently experience hypoglycaemia of less severity and episodes of unrecognized hypoglycaemia are undoubted- ly common [11]. The long-term cerebral consequences of recurrent hypoglycaemia are unclear, but permanent neuropsychological impairment has been suggested $[12,13]$.

The aim of the present study was to study whether moderate hypoglycaemia gives rise to the same vascular response in diabetic patients as has previously been shown in normal man [10]. To that end, total and regional CBF (rCBF) were measure in patients with Type 1 (insulindependent) diabetes mellitus before, during and immediately after insulin-induced hypoglycaemia.

\section{Subjects and methods}

\section{Subjects}

Ten right-handed men with Type 1 diabetes (C-peptide $<0.1$ nmol/l) with a duration of diabetes of $18.4 \pm 3.8$ years (mean $\pm \mathrm{SD}$ ) participated in the study. The age of the patients was 23 to 31 years (mean $26.0 \pm 2.4$ years). No subject was taking any medication other than insulin. The blood pressure was $123 \pm 7 / 76 \pm 5 \mathrm{~mm} \mathrm{Hg}$. The glycated haemoglobin $\mathrm{A}_{1 \mathrm{c}}\left(\mathrm{HbA}_{1 \mathrm{c}}\right)$ concentration was $7.6 \pm 1.0 \%$ (normal value $<5.6 \%$ ) and all patients had experienced symptomatic hypoglycaemia on several occasions prior to the study, some episodes re- 
Table 1. Venous arterialized blood glucose, blood pressure levels, mean arterial blood pressure, respiratory pCO $\mathrm{O}_{2}$ and cerebral resistance before, during and after hypoglycaemia

\begin{tabular}{lllllll}
\hline & $\begin{array}{l}\text { Glucose } \\
(\mathrm{mmol})\end{array}$ & $\begin{array}{l}\text { SBP } \\
(\mathrm{mmHg})\end{array}$ & $\begin{array}{l}\text { DBP } \\
(\mathrm{mm} \mathrm{Hg})\end{array}$ & $\begin{array}{l}\text { MABP } \\
(\mathrm{mm} \mathrm{Hg})\end{array}$ & $\begin{array}{l}\mathrm{pCO}_{2} \\
(\mathrm{mmHg})\end{array}$ & $\begin{array}{l}\text { Cerebral resistance } \\
(\mathrm{mm} \mathrm{Hg})\end{array}$ \\
\hline Before & $5.1(0.9)$ & $122(9.8)$ & $72(5.4)$ & $88.7(6.1)$ & $40(1.8)$ & $1.95(0.42)$ \\
During & $2.0(0.2)$ & $124(11.5)$ & $74(5.7)$ & $90.1(4.9)$ & $40(2.1)$ & $1.74(0.34)^{\mathrm{a}}$ \\
After & $6.1(1.1)$ & $121(10.6)$ & $71(4.6)$ & $87.5(5.5)$ & $40(1.9)$ & $1.46(0.41)^{\mathrm{a}}$ \\
\hline
\end{tabular}

${ }^{a} p<0.01$ compared to values before hypoglycaemia. The blood glucose values during hypoglycaemia are the mean values at the start and end of the hypoglycaemic period. SBP, Systolic blood pressure;
DBP, diastolic blood pressure; MABP, mean arterial blood pressure. Values are given as means (SD). quiring external assistance. No patient had a history of cerebrovascular disease, head injury, serious systemic disease, alcohol abuse or major psychiatric illness. Autonomic neuropathy in the patients was unlikely in the face of normal immediate heart rate response to standing ( $30: 15$ ratio), normal heart rate variations to deep breathing (max-min heart rate) and a normal Valsalva manoeuvre [14]. Informed consent was given by all subjects and the study was approved by the hospital ethics committee.

\section{Protocol}

All subjects used their ordinary insulin regimens on the day before the study. To avoid hypoglycaemia during the night, the bed-time insulin dose was reduced or omitted. The measurements were carried out after an overnight fast. The patients remained in the recumbent position throughout the study. An antecubital venous catheter for infusion of insulin, potassium $(10 \mathrm{mmol} / \mathrm{h})$ and glucose was inserted. Venous blood samples were arterialized by the use of heat blankets, and drawn from a hand vein at 5-10-min intervals for immediate measurements of glucose using a Reflolux $S$ glucose meter (Boehringer Mannheim, Mannheim, FRG) and for later analysis of whole-blood glucose levels by a standard glucose oxidase method (Kodak Ektachem), which represent the data given in Table 1. A constant infusion of regular insulin $\left(2.5 \mathrm{mU} \cdot \mathrm{kg}^{-1} \cdot \mathrm{min}^{-1}\right.$; Actrapid Human; Novo-Nordisk A/S, Copenhagen, Denmark) was administered to reach and maintain the target blood glucose level of $2.0 \mathrm{mmol} / \mathrm{which}$ was reached within $53.0 \pm 6.5 \mathrm{~min}$ (mean $\pm \mathrm{SD}$ ). A graded $20 \%$ glucose infusion was used to maintain this level and to restore normoglycaemia. The following protocol was observed in each patient. We began with a sham measurement under resting conditions, made in the same manner as the other measurements, but with the subject unaware of the content of the infusate (saline vehicle only). The sham measurement was performed in order to minimise for the influence of anxiety, which is one of the most important factors for poor reproducibility. This was followed by CBF evaluations under normoglycaemic conditions, after $10 \mathrm{~min}$ of hypoglycaemia, and at $15 \mathrm{~min}$ following restoration to normoglycaemia. The duration of hypoglycaemia was $25.0 \pm 3.9 \mathrm{~min}$ and the time period to normalisation of blood glucose following hypoglycaemia was $41.0 \pm 8.6 \mathrm{~min}$. There was at least a 30 -min interval between the three periods with a total experimental time of $4 \mathrm{~h}$. Repeated blood pressure measurements with a mercury sphygmomanometer were recorded. Diastolic blood pressure was taken as Korotkoff phase V. Mean arterial blood pressure (MABP) was calculated as diastolic blood pressure + (systolic blood pressure - diastolic blood pressure) $/ 3$ and cerebral vascular resistance as $\mathrm{MABP} / \mathrm{CBF}$.

\section{CBF measurement}

The rCBF distribution was measured by a SPECT (single photon emission computed tomography) camera recording the clearance of intravenously administered xenon 133 [15-18]. The rCBF was measured in five contiguous $2-\mathrm{cm}$ thick slices, parallel to the orbitomeatal line. This gave a three-dimensional distribution of rCBF in the entire brain. The inter-assay variation of coefficient was less than $6 \%$. The resolution within each slice was approximately $2 \mathrm{~cm}$ (full with half maximum, FWHM). Within each slice the rCBF was calculated for regions of interest (ROI) (e.g. frontal, temporal and parietal lobes) that were predetermined from an anatomical brain atlas and scaled to the actual head size [19]. Three-dimensional ROIs were used to calculate the $\mathrm{rCBF}$ in brain regions distributed in more than one slice. To measure the brain volume, the entire brain area in each slice was measured, and the sum of the brain areas from the five slices was multiplied by the slice thickness of $2 \mathrm{~cm}$. During each measurement, the subject was placed in a comfortable supine position with the head resting in the aperture of the camera, a detector for the xenon 133 in the lung was placed over the right mid-thorax, and a tube for evacuation of the exhaled xenon 133 was placed approximately $2 \mathrm{~cm}$ from the face. The subject was instructed to rest motionless, but to keep his eyes open. Attempts were made to minimize noise during the measurements. The xenon 133 was administered intravenously in saline through a $10 \mathrm{~cm}$-long plastic catheter attached to a cannula in the right antecubital vein, and was immediately followed by a rapid infusion of $20 \mathrm{ml}$ saline.

\section{Statistical analysis}

Measured values are given as the mean (SD). The cerebrovascular resistance, cerebral volume values and the CBF during and following hypoglycaemia were compared with those obtained before hypoglycaemia, and were evaluated by Student's paired $t$-test. No mass significance (Bonferroni) correction was used in calculation of the significance of the $t$-values. The statistical changes in ICBF values were calculated by a repeated measures ANOVA with correction for departure from spericity of the data [20]. The correlation of the mean CBF and cerebral volume values with the blood glucose, glucose fall rate, time during hypoglycaemia and restitution time were calculated by linear regression.

\section{Results}

During the period of hypoglycaemia, the target blood glucose concentration was achieved. As shown in Table 1, a small not statistically significant, increase in systolic, diastolic and mean arterial blood pressure levels was seen during hypoglycaemia. The respiratory $\mathrm{pCO}_{2}$ was unchanged during all three measurements. Cerebrovascular resistance fell by $11 \%$ during hypoglycaemia and by $25 \%$ during the recovery period compared to before hypoglycaemia $(p<0.01)$.

Mean CBF before hypoglycaemia was $49.5 \pm 3.7 \mathrm{ml}$. $100 \mathrm{~g}^{-1} \cdot \mathrm{min}^{-1}$ (mean $\pm \mathrm{SD}$ ) and increased during hypoglycaemia to $55.8 \pm 4.5 \mathrm{ml} \cdot 100 \mathrm{~g}^{-1} \cdot \min ^{-1}(p<0.01)$ with a further increase to $59.4 \pm 4.5 \mathrm{ml} \cdot 100 \mathrm{~g}^{-1} \cdot \mathrm{min}^{-1}(p<0.05)$ 15 min after normalization of the blood glucose level. In six 


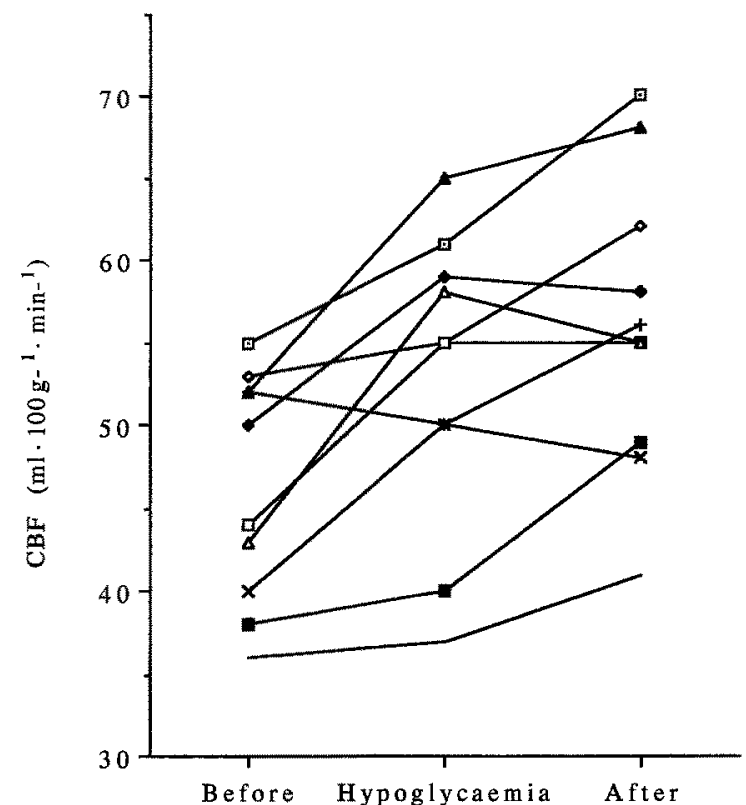

Fig. 1. Individual cerebral blood flow (CBF) values $\left(\mathrm{ml} \cdot 100 \mathrm{~g}^{-1}\right.$. $\min ^{-1}$ ) before, during and after hypoglycaemia in 10 Type 1 diabetic patients

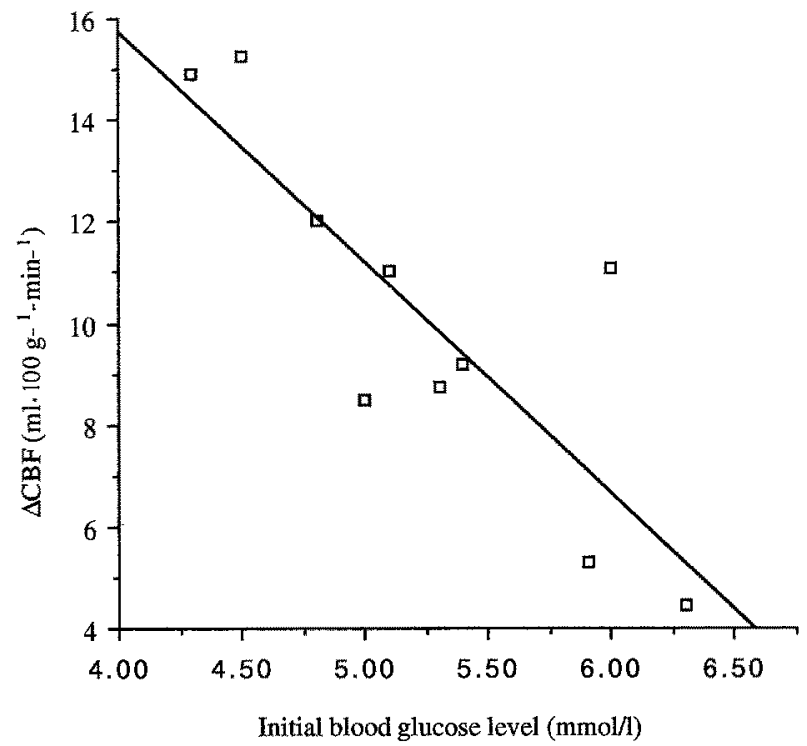

Fig. 2. The relation between the change in mean cerebral blood flow (CBF) from before hypoglycaemia to after recovery, and the blood glucose level before initiation of hypoglycaemia. $y=33.97-$ $4.5517 x ; R=0.82$. The correlation is highly significant $(p<0.003)$. Note that a high initial blood glucose predisposes to a small CBF change

out of ten patients the maximum CBF occurred during the recovery phase (Fig. 1). The mean CBF increase from before hypoglycaemia to the recovery phase correlated with the blood glucose level before hypoglycaemia, with less CBF increase at higher initial glucose levels $(p<0.003$; Fig. 2). The CBF increase also correlated ( $p<0.01 ;$ Fig. 3 ) with the rate of blood glucose decrease during initiation of hypoglycaemia. There was no correlation between the $\mathrm{CBF}$ increase and the initial CBF level.

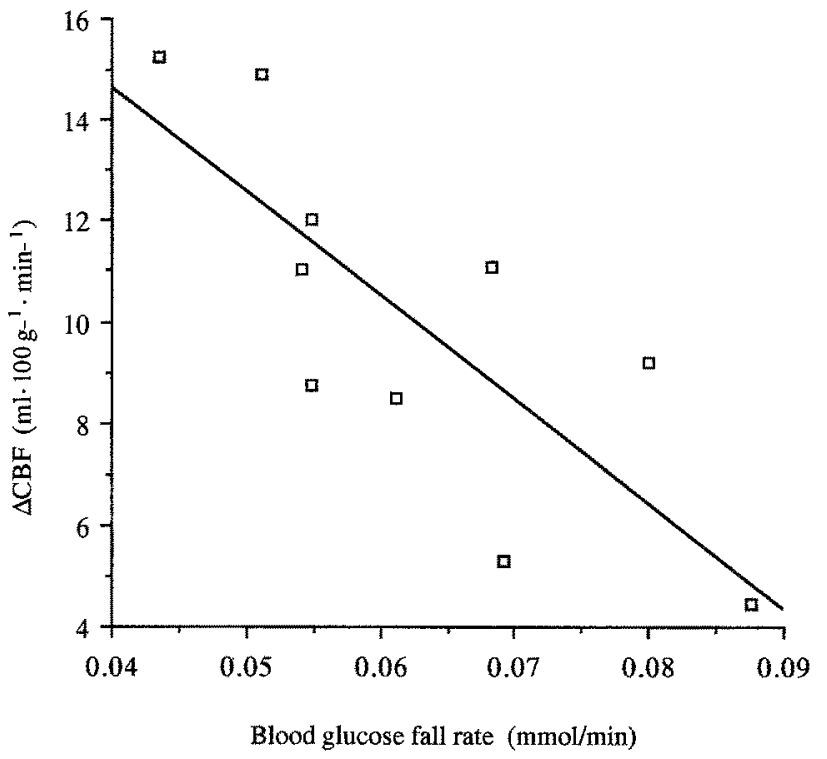

Fig.3. The relation between the change in mean cerebral blood flow (CBF) from before hypoglycaemia to after recovery, and the rate of blood glucose decrease during initiation of hypoglycaemia. $y=22.8534-205.3374 x ; R=0.78$. The correlation is significant $(p<0.01)$. Subjects with a low CBF increase show less resistance to lowering of the blood glucose level

The highest rCBF values before hypoglycaemia were found in the basal ganglia and insula and the lowest in the parietal lobe and in the white matter.

The changes in regional distribution of $\mathrm{CBF}$ during hypoglycaemia are shown in Figure 4. Hemispheric asymetry in $\mathrm{rCBF}$ was found at all three measurements affecting all regions, the rCBF being higher on the right side. The differences between the two hemispheres were $1.7 \pm 0.7(p<0.001), 1.6 \pm 1.5(p<0.01)$ and $1.7 \pm 1.5 \mathrm{ml}$. $100 \mathrm{~g}^{-1} \cdot \mathrm{min}^{-1}$ before, during and after hypoglycaemia, respectively. No significant redistribution of $\mathrm{rCBF}$ was found during or after hypoglycaemia.

Changes in the brain volume from before hypoglycaemia to the recovery phase were found to be the sum of effects working in opposite directions. Deeper hypoglycaemia was associated with a more pronounced decrease in brain volume ( $p<0.003$; Fig. 5), while the length of the restitution time after hypoglycaemia correlated with a volume increase $(p<0.03 ;$ Fig. 6). In consequence of these opposing effects there was no mean change in the brain volume.

\section{Discussion}

The results of the present study of diabetic patients show that a marked increase $(12.8 \%)$ in CBF occurs when the blood glucose level is lowered to $2.0 \mathrm{mmol} / \mathrm{l}$ with a further $6.4 \%$ increment when measured 15 min after recovery. In our earlier study [10] where the blood glucose was lowered in the same manner to $2.0 \mathrm{mmol} / \mathrm{l}$ in normal subjects, the mean $\mathrm{CBF}$ increase was somewhat greater during hypoglycaemia $(19.9 \%)$, but there was little further CBF increase after recovery. The mean CBF before and after hy- 


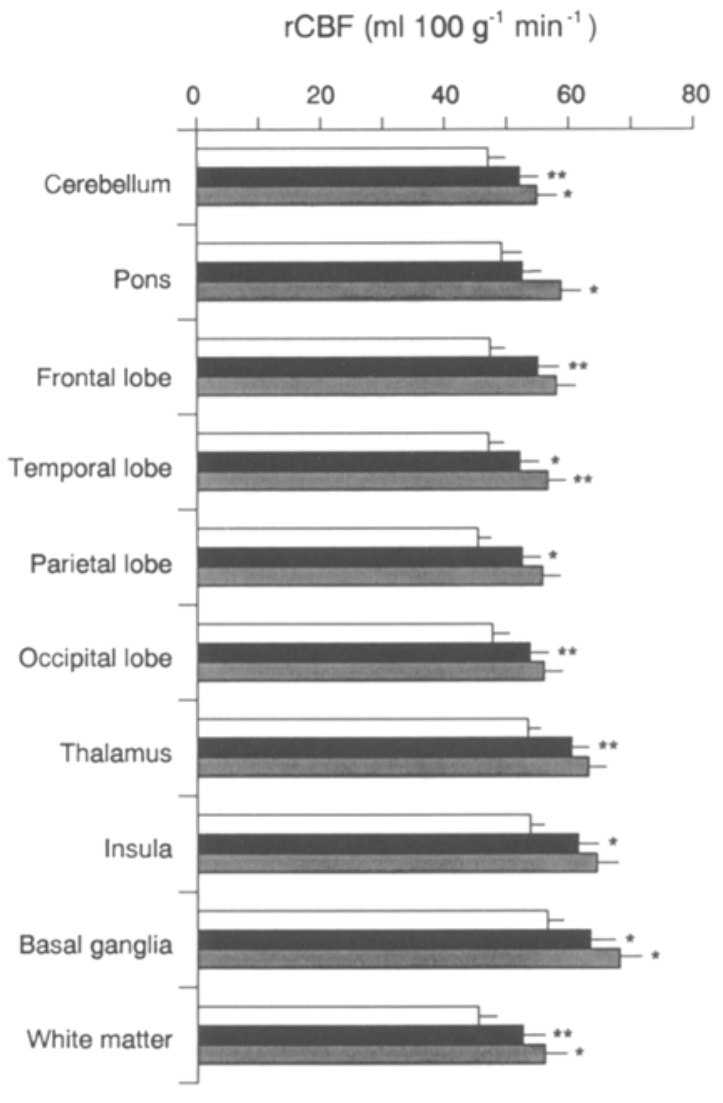

Fig.4. Regional distribution of cerebral blood flow (rCBF) $\left(\mathrm{ml} \cdot 100 \mathrm{~g}^{-1} \cdot \min ^{-1}\right)$ before ( $\left.\square\right)$, during ( $\left.\mathbf{a}\right)$ and after ( caemia in 10 diabetic patients. Values are given as means \pm SEM and represent mean values of right and left hemispheres.

${ }^{*} p<0.05$ and ${ }^{* *} p<0.01$ compared to previous measurement

poglycaemia in our diabetic patients was significantly $(p<0.05)$ higher than in the normal subjects. Speculatively, the higher initial CBF level in the diabetic patients may be an effect of their chronic hyperglycaemia. Furthermore, the patients had an early onset of diabetes, and exposure to hypoglycaemia on the developing brain can be profound. In this respect this group of patients may not be representative of patients who develop their diabetes in adulthood.

The finding that subjects with higher initial blood glucose levels had a decreased ability for a CBF increase may reflect a deficiency of the homeostatic functions that normally counteract and compensate for hypoglycaemia. Thus, subjects with low CBF changes generally had a higher rate of blood glucose decrease during initiation of hypoglycaemia. A slow fall in blood glucose was associated with a larger increase in CBF which may represent a temporal adaptation to the development of hypoglycaemia. The finding of a relationship between a high initial blood glucose level and a less pronounced increase in $\mathrm{CBF}$ is in accord with findings in experimental studies where chronic hyperglycaemia leads to a decrease in the maximum glucose transport capacity of the blood-brain barrier [21]. However, the concept of blood-brain barrier glucose transport repression has been questioned by others [22].

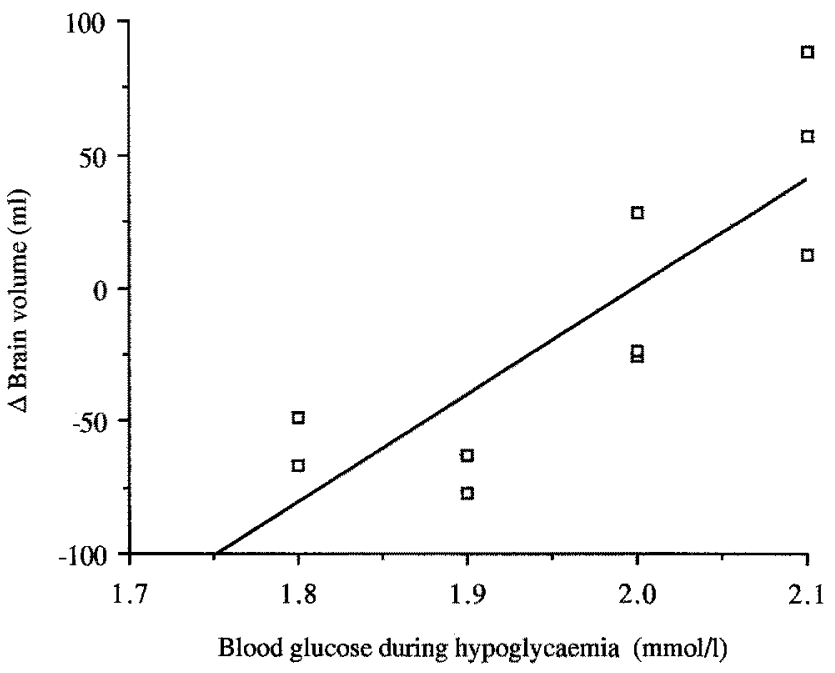

Fig.5. The relation between the change in brain volume from before hypoglycaemia to after recovery, and the blood glucose level during hypoglycaemia. $y=-808+404 x ; R=0.84$. The correlation is highly significant $(p<0.003)$. The lower the blood glucose level during hypoglycaemia, the greater the reduction in brain volume

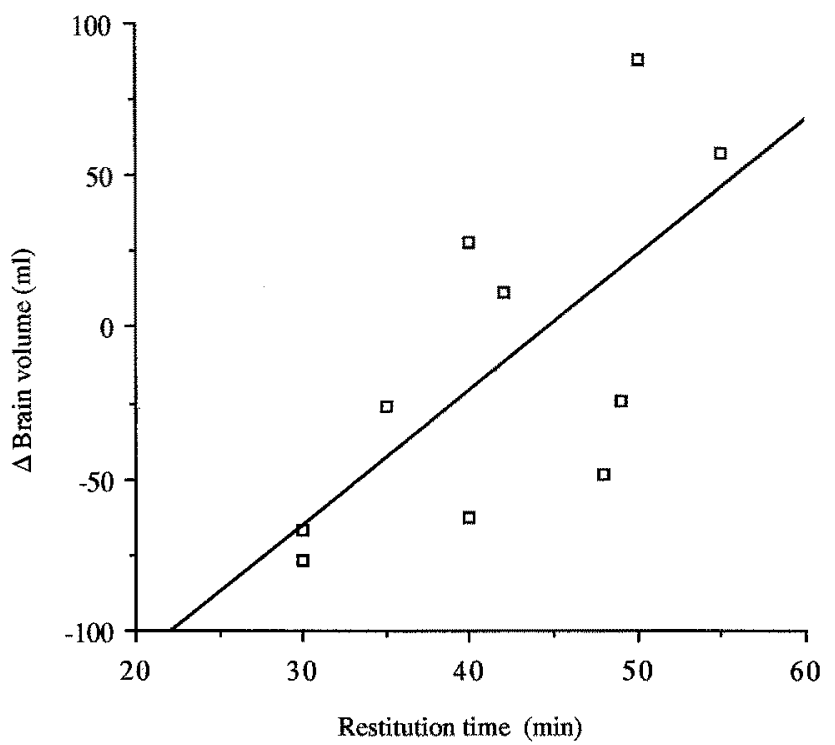

Fig.6. The relation between the change in brain volume from before hypoglycaemia to after recovery, and the time for restitution of the blood glucose after hypoglycaemia. $y=-197.7391+4.43 x$; $R=0.68$. The correlation is significant $(p<0.05$ ). The longer the restitution time, and consequently the later the CBF measurement, the more pronounced the increment in brain volume

Insulin-induced hypoglycaemia has been widely used in the study of CBF and energy metabolism and there has been some disagreement as to the effect of hypoglycaemia on CBF. Most studies have used animal models, some of which have reported no effect on $\mathrm{CBF}$, whereas others reported $\mathrm{CBF}$ to be increased during hypoglycaemia $(6,23-$ $25)$. The conflicting results may be due to differences in species studied, methods used to measure CBF, experimental design or to the degree of hypoglycaemia or a combination.

There seems to be little doubt, however, that CBF can be markedly increased following acute severe hypogly- 
caemia. In this study we clearly demonstrate that even moderate hypoglycaemia leads to a significant increase in rCBF. Measurements of CBF in therapeutic insulin coma in psychiatric patients have shown conflicting results. An average increase in $\mathrm{CBF}$ of $38 \%$ compared to baseline values has been reported [8] while others did not find any changes [26]. Neil et al. [27] used an intravenous xenon 133 clearance technique to measure $\mathrm{CBF}$ in diabetic patients during more severe hypoglycaemia (nadir blood glucose $1.3 \pm 0.5 \mathrm{mmol} / \mathrm{l}$ ). In that study CBF increased by $17 \%$ during hypoglycaemia and remained elevated $1 \mathrm{~h}$ after hypoglycaemia was reversed. They found a $16 \%$ fall in cerebrovascular resistance during hypoglycaemia compared to $11 \%$ in the present study in which the hypoglycaemia was less severe. Carbon dioxide $\left(\mathrm{CO}_{2}\right)$ is known to be a potent vasodilator [28], but in the present study the minute and non-significant fluctuations in end-tidal $\mathrm{CO}_{2}$ did no explain the changes in CBF.

The resting CBF in the present study is lower than previously reported for SPECT measurements $[29,30]$. This can probably be explained in two ways, namely (a) the subjects were not required to use a face mask for inhalation of xenon 133, and (b) the sham measurements performed before the real recordings familiarized the subjects with the experimental situation. Thus, it can be argued that the increased CBF during hypoglycaemia was not due to anxiety. Furthermore, the $\mathrm{CBF}$ continued to increase in the recovery period following hypoglycaemia, which would not be the case if anxiety was caused by hypoglycaemia.

In their study of normal three-dimensional distribution of CBF, Devous et al. [30] found slightly higher right-sided hemispheric flows except in the frontal and parietal lobes. This observation was confirmed in the present study where right hemispheric CBF was consistently higher compared to all regions on the left side both before, during and after hypoglycaemia.

The brain volume of the Type 1 diabetic patients was affected in two ways by hypoglycaemia: first, a volume reduction which was more pronounced the lower the blood glucose level during hypoglycaemia, and secondly a volume increase with longer restitution time after hypoglycaemia. Although the brain volume of the diabetic patients was significantly affected by hypoglycaemia there was no mean volume reduction from before hypoglycaemia to the recovery period. This differs from our findings in normal subjects [10] where a volume reduction was found. The lower brain volume of the diabetic patients may, like the higher CBF be attributed to previous insulin treatment. The rise in haematocrit which occurs during hypoglycaemia [31] results from catecholamine-induced haemoconcentration and thus a reduction in plasma volume [32]. The extravasation of fluid could hypothetically lead to an increase in cerebral volume.

Acknowledgements. This study was supported by grants from The Medical Faculty, University of Lund, the Swedish Diabetes Federation, the Swedish Society of Medicine, Hoechst Foundation and the Swedish Medical Research Council (Grants no. B88-04x-0008424C and B91-14x-00084-27A). The technical assistance from K.Lantz, M.Persson and R. Sawaya is gratefully acknowledged.

\section{References}

1. Pramming $\mathrm{S}$, Thorsteinsson $\mathrm{B}$, Theilgaard A, Pinner EM, Binder C (1986) Cognitive function during hypoglycaemia in type 1 diabetes mellitus. Br Med J 292: 647-650

2. Holmes CS, Hayford JT, Gonzales JL, Weydert JA (1983) A survey of cognitive functioning at different glucose levels in diabetic persons. Diabetes Care 6: 180-185

3. Blackman JD, Towle VL, Lewis GF, Spire JP, Polonsky KS (1990) Hypoglycemic thresholds for cognitive dysfunction in humans. Diabetes 39: 828-835

4. Pramming S, Thorsteinsson B, Stigsby B, Binder C (1988) Glycemic threshold for changes in electroencephalograms during hypoglycaemia in patients with insulin-dependent diabetes. BrMed J 296: 665-667

5. Tallroth G, Lindgren M, Stenberg G, Rosén I, Agardh C-D (1990) Neurophysiological changes during insulin-induced hypoglycaemia and in the recovery period following glucose infusion in type 1 (insulin-dependent) diabetes mellitus and in normal man. Diabetologia 33: 319-323

6. Abdul-Rahman A, Agardh C-D, Siesjö BK (1980) Local cerebral blood flow in the rat during severe hypoglycemia and in the recovery period following glucose injection. Acta Physiol Scand 109:307-314

7. Siesjö BK, Abdul-Rahman A (1979) Delayed hypoperfusion in the cerebral cortex of the rat in the recovery period following severe hypoglycemia. Acta Physiol Scand 106: 375-376

8. Della Porta P, Maiolo AT, Negri VU, Rosella E (1964) Cerebral blood flow and metabolism in therapeutic insulin coma. Metabolism 13: 131-140

9. Eisenberg S, Seltzer H (1962) The cerebral metabolic effects of acutely induced hypoglycemia in human subjects. Metabolism 11: $1162-1168$

10. Tallroth G, Ryding E, Agardh C-D (1992) Regional cerebral blood flow in normal man during insulin-induced hypoglycemia and in the recovery period following glucose infusion. Metabolism 41: 717-721

11. Cryer PE (1988) Hypoglycemia and insulin-dependent diabetes mellitus. In: Alberti KGMM, Krall LP (eds) The Diabetes Annual Vol 4. Elsevier, Amsterdam New York Oxford, pp 272-310

12. Wredling R, Levander S, Adamson U, Lins PE (1990) Permanent neuropsychological impairment after recurrent episodes of severe hypoglycaemia in man. Diabetologia 33: 152-157

13. Langan SJ, Deary IJ, Hepburn DA, Frier BM (1991) Cumulative cognitive impairment following recurrent severe hypoglycaemia in adult patients with insulin-treated diabetes mellitus. Diabetologia 34: 337-344

14. Ewing DJ, Martyn CN, Young RJ, Clarke BF (1985) The value of cardiovascular autonomic function tests: 10 years experience in diabetes. Diabetes Care 2: 491-498

15. Stokely EM, Sveinsdottir E, Lassen NA (1980) A single photon dynamic computer-assisted tomograph (DCAT) for imaging brain function in multiple cross-sections. J Comput Assist To$\operatorname{mogr} 4: 230-240$

16. Kanno N, Lassen A (1979) Two methods for calculating regional cerebral blood flow from emission computed tomography of inert gas concentrations. J Comput Assist Tomogr 3: 71-76

17. Stokely EM (1985) Regional multiparameter estimation of tomographic diffusable tracer clearance curves: modification of the double-integral method. J Cereb Blood Flow Metab 5: 133-141

18. Celcis P, Goldman T, Henriksen L, Lassen NA (1981) A method for calculating regional cerebral blood flow from emission computed tomography of inert gas concentrations. Comput Assist Tomogr 5: 641-645

19. Kretschmann HJ, Weirinch W (1986) Neuroanatomy and cranial computed tomography. Thieme Verlag, Stuttgart

20. Kirk RI (1982) Experimental design. Brooks, Monterey

21. Gjedde A, Crone C (1981) Blood-brain glucose transfer: repression in chronic hyperglycemia. Science $244: 456-457$

22. Pelligrino DA, Lipa MD, Albrecht RF (1990) Regional bloodbrain glucose transfer and glucose utilization in chronically 
hyperglycemic, diabetic rats following acute glycemic normalization. J Cereb Blood Flow Metab 10: 774-780

23. Bryan RM, Hollinger BR, Keefer KA, Page RB (1987) Regional cerebral and neural lobe blood flow during insulin-induced hypoglycemia in unanesthetized rats. J Cereb Blood Flow Metab 7: 96-102

24. Ghajar JB, Plum F, Duffy TE (1982) Cerebral oxidative metabolism and blood flow during acute hypoglycemia and recovery in unanesthetized rats. J Neurochem 38:397-409

25. Gardiner RM (1980) The effect of hypoglycemia on cerebral blood flow and metabolism in the newborn calf. J Physiol 298: $37-51$

26. Kety SS, Woodford RB, Harmel MH, Freyhan FA, Appel KE, Schmidt CF (1948) Cerebral blood flow and metabolism in schizophrenia. Am J Psychiatr 104: 765-770

27. Neil HAW, Gale EAM, Hamilton SJC, Lopez-Espinoza I, Kaura R, McCarthy ST (1987) Cerebral blood flow increases during insulin-induced hypoglycaemia in type 1 (insulin-dependent) diabetic patients and control subjects. Diabetologia 30: $305-309$

28. Griffith DNW, Saimbi S, Lewis C, Tolfree S, Betteridge DJ (1986) Abnormal cerebrovascular carbon dioxide reactivity in people with diabetes. Diabetic Med 4:217-220
29. Shirahata N, Henriksen L, Vorstrup S et al. (1985) Regional cerebral blood flow assessed by $133 \mathrm{Xe}$ inhalation and emission tomography: normal values. J Comp Assist Tomogr 9: 861-866

30. Devous MD, Stokely EM, Chehabi HH, Bonte FJ (1986) Normal distribution of regional cerebral blood flow measured by dynamic single-photon emission tomography. J Cereb Blood Flow Metab 6: 95-104

31. Frier BM, Corrall RJM, Davidson NMcD, Webber RG, Dewar A, French EB (1983) Peripheral blood cell changes in response to acute hypoglycaemia in man. Eur $J$ Clin Invest 13: 33-39

32. Hilsted J, Bonde-Petersen F, Madsbad S et al. (1985) Changes in plasma volume, in transcapillary escape rate of albumin and in subcutaneous blood flow during hypoglycaemia in man. Clin Sci 69: $273-277$

Received: 16 September 1992

and in revised form: 4 February 1993

Dr. C.-D.Agardh

Department of Internal Medicine

University Hospital

S-22185 Lund

Sweden 